\title{
IN VIVO THERAPEUTIC EFFICACY OF TWO RUTHENIUM COMPLEXES AND TUMOR REGRESSION IN DALTON'S LYMPHOMA ASCITES TUMOR MODEL
}

\section{Gunjan Sharma and Biplob Koch* \\ Department of Zoology, Institute of Science, Banaras Hindu University, Varanasi-221005, U.P., India}

\begin{abstract}
*Corresponding Author Email: kochbiplob@gmail.com
ABSTRACT

The purpose of this study is to evaluate in vivo antitumor efficacy of two arene ruthenium complexes, [( $n 6$-arene) RuCl (2-pcdpm)] complex 1 and [(n6-arene) RuCl(4-mtdpm)] complex 2 (n6-arene = C10H14), containing new chelating ligands [(2-pcdpm) = 4-(2-methoxypyridyl)-phenyldipyrromethene] and [4-mtdpm = 5-(4methylthiophenyl)-dipyrromethene] respectively. Recently, we reported their potential anticancer activity in vitro on murine lymphoma [Dalton's lymphoma (DL)] cells. There are several drugs which exhibit potential anticancer activity in vitro condition but losing their efficacy when applied to in vivo condition. Therefore, both complexes were further investigated in vivo for their antitumor activity on tumor model system ( $D L$ bearing mice) along with most common drug cisplatin as positive control. Both the complexes exhibit substantial increased in their antitumor activities by increasing the life span of murine lymphoma mice with approximately 2.5 fold as compared to control and 1.4 fold as compared to most widely used chemotherapy regimen cisplatin. Further, the complexes also significantly reduced body weight and belly size growth pattern of lymphoma bearing mice. Thus, in vivo studies indicate that both complexes can be helpful for consideration as therapeutic agents in cancer treatment.
\end{abstract}

\section{KEY WORDS}

Antitumor activity, Dalton's lymphoma (DL), in vivo, tumor regression.

\begin{abstract}
INTRODUCTION:
In order to search for alternative cancer chemotherapy, significant research efforts have been devoted for finding of unique anticancer drugs which have minimum side effects on in vivo system. Conventional drug development process involves, in vitro testing followed by safety measure as well as efficiency of drugs in clinical trials. At present days in cancer chemotherapy, cisplatin and related inorganic drugs are being frequently used to treat many cancer types [1, 2]. Although several tribulations are associated with their use like high toxicity leading to side effects and limitations in dose/cycle that can be administrated [3]. Improved knowledge in platinum drugs design and administration procedures have some way to reduce the toxicity of these complexes $[4,5,6]$. On the other hand, non-platinum metal
\end{abstract}

based complexes have also been investigated for their possible use as anticancer drugs. In this context, Ruthenium (Ru) complexes have attracted much attention because of their unique properties like biocompatibility, stability and many more relevant characteristics. $\mathrm{Ru}$ is one of the most promising metals of transition metal series and its complexes are emerging as unique anticancer drugs in preclinical developments and two complexes (NAMI$A$ and KP1019) are currently in clinical trials [7-11]. As compared to platinum drugs, ruthenium complexes exert lower general toxicity which has been attributed to the ability of ruthenium compounds to specifically act on cancer cells $[12,13]$.

Previously, we reported syntheses, characterization, DNA binding and anticancer activity in vitro on murine lymphoma [Dalton's lymphoma (DL)] cells of 
two ruthenium complexes, [(n6-arene) RuCl(2pcdpm)] complex 1 and [(n6-arene) RuCl(4-mtdpm)] complex 2 (n6-arene $=\mathrm{C} 10 \mathrm{H} 14)$, containing new chelating ligands $[(2-p c d p m)=4-(2-$ methoxypyridyl)phenyldipyrromethene] and [4-mtdpm = 5-(4-

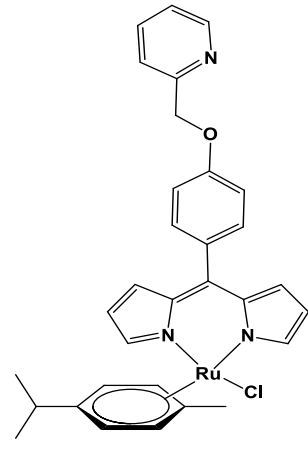

Complex 1

\section{MATERIALS AND METHODS:}

\section{Animals and Dalton's Lymphoma (DL) cells:}

Initially, Balb/c mice were maintained and inbred under standard laboratory conditions as per the guidelines of the Institutional Animal Ethical Committee (IAEC), Banaras Hindu University; at $25^{\circ} \mathrm{C}$ with 12:12 hours light/dark cycle and mice were fed standard rodent chow with drinking water ad libitum. 12 to 14 week old healthy Balb/c male mice of 25-30gram body weight (B. W.) were used for this experiment.

Dalton's Lymphoma designated as (DL) is a transplantable $\mathrm{T}$ cell lymphoma that spontaneously originates in thymus of DBA strain $(\mathrm{H}-2 \mathrm{~d})$ of mice [16]. It can be maintained by serial transplantation in intraperitoneal cavity of one mouse to other mouse and it mimics some lymphoma and leukemia of human origin [17].

\section{DL transplantation and treatment plan:}

Under aseptic conditions, $1 \times 10^{6}$ viable Dalton's Lymphoma (DL) cells in $1 \mathrm{~mL}$ of PBS were inoculated / transplanted intraperitoneally in all mice to establish the ascites tumor and day of DL transplantation count as day zero (0). Development of DL intraperitoneally was confirmed by abnormal swelling and increased body weight, which were clearly noticeable after day 10 of transplantation and generally $D L$ bearing mice survived for only $18 \pm 2$ days. The success rate of DL development is $100 \%$. [18]. methylthiophenyl)-dipyrromethene] respectively $[14,15]$. Herein, we describe the in vivo antitumor activity of both Ru complexes on tumor bearing mice model.

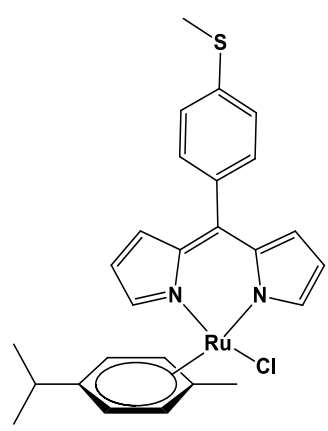

Complex 2

Standard anticancer drug cisplatin (purchased from Cipla with given name cisplatin injection BP Cytoplatin-50 Aqueous, each $50 \mathrm{ml}$ vial contains: cisplatin IP 50mg, sodium chloride IP $0.9 \% \mathrm{w} / \mathrm{v}$ and water) were used as positive control. Initially, maximum tolerable dose (MTD) for positive control (cisplatin) and both ruthenium arene complexes were determined and drugs were administered intraperitoneally (i.p., standard route for this model) at its MTD and lower dose.

DL transplanted mice were randomly divided into three groups $(n=6)$ as follows: Control group, Complex 1treated group and Complex 2 treated group. Control group was further divided into two subgroups; PBS control (as negative control) and cisplatin (5 mg/kg B.W) treated (as positive control) group. Likewise, Complex 1 and Complex 2 groups were divided into two subgroups; $5 \mathrm{mg} / \mathrm{kg} \mathrm{B.W}$. and $10 \mathrm{mg} / \mathrm{kg}$ B.W. according to two different doses. Cisplatin and two different doses of both complexes were administered in respective groups at 6th, 12th and 18th day of DL transplantation and negative control group was given the same volume of vehicle. In vivo survival assays and tumor growth measurement:

Enhancement in the survival time of DL bearing mice by the treatment of both complexes were evaluated by Kaplan-Meier survival curve and antitumor efficacy of drugs were further assessed by computing Treated ( $\mathrm{T})$ /Control $(\mathrm{C})$ value. 
Briefly, for the survival analysis, results are expressed as percent of mean survival time of treated animals ( $T$ ) over mean survival time of the control (C) group [19]. Antitumor activity of complexes was evaluated by computing the T/C value which is the median survival days of treated $(T)$ group divided by that of control (C) group. The ratio of $\mathrm{T} / \mathrm{C}$ value represents as a percentage and if a compound has a T/C percentage $\geq 120 \%$, termed as active complex [20, 21].

$\mathrm{T} / \mathrm{C}$ value was calculated according to the formula: $\mathrm{T} / \mathrm{C} \%=[$ Median survival days of treated $(\mathrm{T})$ group /Median survival days of control (C) group] $\times 100$ According to $\mathrm{NCl}$ criteria, T/C \% exceeding 120 and increased life span $\geq 20 \%$ indicate that the drug has significant antitumor activity. The antitumor efficacy of both complexes was compared with cisplatin, standard chemotherapeutic drugs as positive control.

Increments in body weight and belly size were consistently measured at day $0,3,6,9,12,15$ and 18 because in case of ascites tumor model, increasing body weight represent tumor mass and increment in belly size is equivalent to tumor volume growth. Belly size was measured with vernier calipers. The belly size (tumor volume) was calculated from two dimensional measurements [22] and formula:

Tumour volume $\left(\mathrm{Cm}^{3}\right)=\left(\mathrm{a} \times \mathrm{b}^{2}\right) / 2$

Where $a$ and $b$ are the tumor length and width $(\mathrm{Cm})$ respectively.

\section{Statistical analysis:}

Statistical analyses were performed using software SPSS (version 16). The results are expressed as the mean \pm standard error mean (S.E.) and compared with the control group $(n=6)$. Data were analyzed by chi-square test and the analysis of variance (One-way ANOVA) followed by Tukey post hoc test. A p value < 0.05 was considered as statistically significant.

\section{RESULTS AND DISCUSSION:}

\section{Enhancement of survival of DL bearing Mice:}

In vivo study refers to real and natural physiological conditions, which can confirm the actual potency of complexes to act as anticancer drugs. Therefore, to evaluate the in vivo antitumor aspect of complexes, both ruthenium arene complexes were tested on animal tumor model (Dalton's Lymphoma bearing mice). In order to test the antitumor activity, the drugs were administered intraperitoneally in tumor bearing mice. Results showed a significant inhibition of tumor growth compared to the control group. More importantly, median lifespan/survival days of tumor bearing mice treated with complexes were significantly increased as compared to that of untreated tumor bearing mice suggesting that the treatment affected viability of cancerous cells, but have no effect/least effect on normal cells. Enhancement in the longevity of comp. 1 and $\mathbf{2}$ treated groups as compared to the negative control and survival data were analyzed by Kaplan-Meier survival curve using log-rank statistics suggested a significant dose-dependent increase in survival by approximately 1.8 fold and 2.4 fold with dose of 5 and $10 \mathrm{mg} / \mathrm{kg}$ B.W. of comp. 1, whereas comp. 2 at both doses $(5 \mathrm{mg} / \mathrm{kg}$ and $10 \mathrm{mg} / \mathrm{kg}$ ) increased 1.8 fold and 2 respectively 2.5 -fold longevity respectively (Fig. 1). Furthermore, if we compared with positive control (cisplatin treated tumor bearing mice) to both complexes at $10 \mathrm{mg} / \mathrm{kg} \mathrm{B.W}$. increased approximately 1.4 fold of survivability. Consistent with this, we find that administration of drugs at same dose to normal mice did not cause any major side effects as observed and survived normally. Thus, comp. 1 and $\mathbf{2}$ could be used as a potential cancer therapeutic agent.

Evaluation of Treated/Control (T/C) values of complexes:

Maximum tolerable dose (MTD) of Cisplatin, comp.1 and 2 were analyzed and it was $5 \mathrm{mg} / \mathrm{kg}, 10 \mathrm{mg} / \mathrm{kg}$ and $10 \mathrm{mg} / \mathrm{kg}$ B.W. respectively. MTD data indicate that both $\mathrm{Ru}$ complexes were less toxic and more tolerable than Cisplatin drug. Antitumor activity of both complexes was assessed in accordance to National Cancer Institute ( $\mathrm{NCl}, \mathrm{U}$. S.) standard protocol for in vivo primary screening. The Treated/ Control (T/C) values are given in figure 2 and Table 1. Data indicate the very high antitumor activity of both $\mathrm{Ru}$ complexes on DL bearing mice. The $\mathrm{T} / \mathrm{C}$ values were $237 \%$ and $247 \%$ when treated on the 6 th, 12 th and 18th day after DL transplantation with comp. 1 and 2 respectively at higher dose. However, the T/C value of cisplatin was equivalent and nearly comparable to lower doses of both complexes.

For the development of new therapeutics in nonclinical research, it is necessary to investigate complexes from in vitro to in vivo models and in vivo 
studies reflects more clear views regarding real potential of any drug. Among the transition metal compounds, ruthenium appears to be more potential candidate with different chemistry from cisplatin and its analogs. Hypoxic environment of many tumors may be one of the basics causes of cancer cell selectivity or preferences by reducing the Ru III to Ru II complexes species, which binds rapidly [23]. In in vivo experiment, both complexes were tested for antitumor action on DL bearing mice and also compared with cisplatin treated groups in different parameters like survival days, $\mathrm{T} / \mathrm{C}$ value, body weight and belly size growth pattern. Before antitumor study, the major differences were observed in maximum tolerable dose (MTD) which indicates that as compared to cisplatin drug, both Ru-arene complexes are more tolerable or less toxic in in vivo condition.

Regression in body weight and belly size growth pattern:

In ascites tumor model system, increment in tumor mass and tumor volume can be detected by body weight and belly size growth pattern respectively. Both comp. 1 and $\mathbf{2}$ demonstrated tumor growth inhibition in respect to both body weight and belly size (Fig. 3A and 3B). Increment in body weight of control, cisplatin (5mg/kg B.W.), comp. 1 (10 mg/kg B.W.) and comp. 2 (10 mg/kg B.W.) treated groups were approximately $21.3 \mathrm{~g}, 16.8 \mathrm{~g}, 13.1 \mathrm{~g}$ and $13.5 \mathrm{~g}$ respectively. Whereas increment in belly size of control, cisplatin (5mg/kg B.W.), comp.1 (10 mg/kg B.W.) and comp.2 (10 mg/kg B.W.) treated groups were approximately $15.7 \mathrm{~cm}^{3}, 11.8 \mathrm{~cm}^{3}, 9.4 \mathrm{~cm}^{3}$ and $9 \mathrm{~cm}^{3}$ respectively. Maximum inhibition in body weight and belly size growth rate was observed in higher dose of comp.1 and $\mathbf{2}$ treated groups. Clearly, comp.1 and $\mathbf{2}$ exhibited potential therapeutic efficiency in tumor bearing mice at the dose of 10 $\mathrm{mg} / \mathrm{kg}$. These results indicate that both complexes offer advantages of decreased side effects and improved drug tolerance. It may suggest that the comp. 1 and 2 may provide promising platform for safe and efficient cancer chemotherapy. Similar in vivo study has been performed with rutheniumDMSO complexes in which they reported that complexes increased longevity of tumor bearing mice and have also been effective against several murine models including a cisplatin resistant $\mathrm{P}$-388 leukemia [24]. In another literature, effect of RAPTA-C was studied in EAC cells isolated from peritoneal cavity of tumor bearing mice and reported that RAPTA-C induced apoptosis in dose dependent manner [25]. The antitumor action of ruthenium complexes might be the consequences of reasonably good penetration within the cancer cells, binding efficiently to DNA and with proteins also $[26,27]$. It is also reported that some of them like Ru III modified its structural conformation after binding with DNA [28]. However, dose dependent reductions in tumor growth were also reported by a $\mathrm{Ru}$ (II)-CNEB complexes by apoptotic induction through declination in lactate dehydrogenase and mitochondrial dysfunction without affecting the normal cells [29].

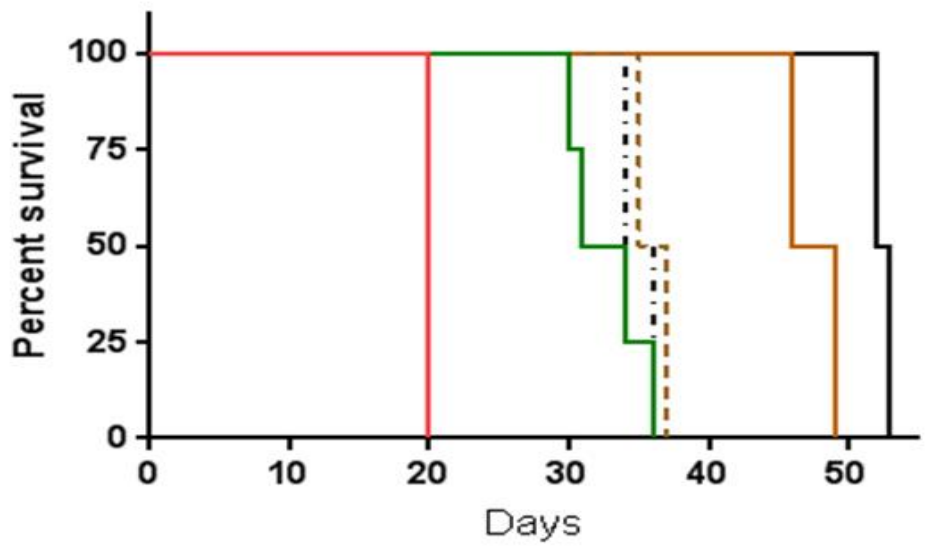

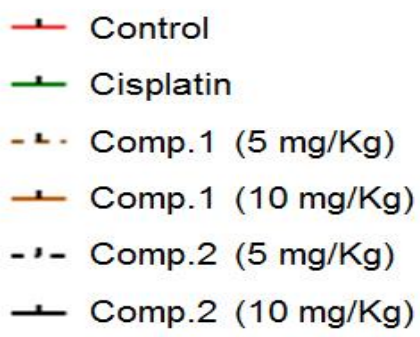

Figure 1: Kaplan-Meier survival curve for survival of Dalton's lymphoma (DL) bearing mice as control and DL bearing treated mice with comp. 1 and 2 at two different ( 5 and $10 \mathrm{mg} / \mathrm{kg} \mathrm{B.W.)} \mathrm{doses.} \mathrm{Graph} \mathrm{was} \mathrm{plotted} \mathrm{and}$ analyzed by Prism 6 software with log-rank analysis to examine the level of significance and $P<0.001$ was obtained in between control and treated groups. 


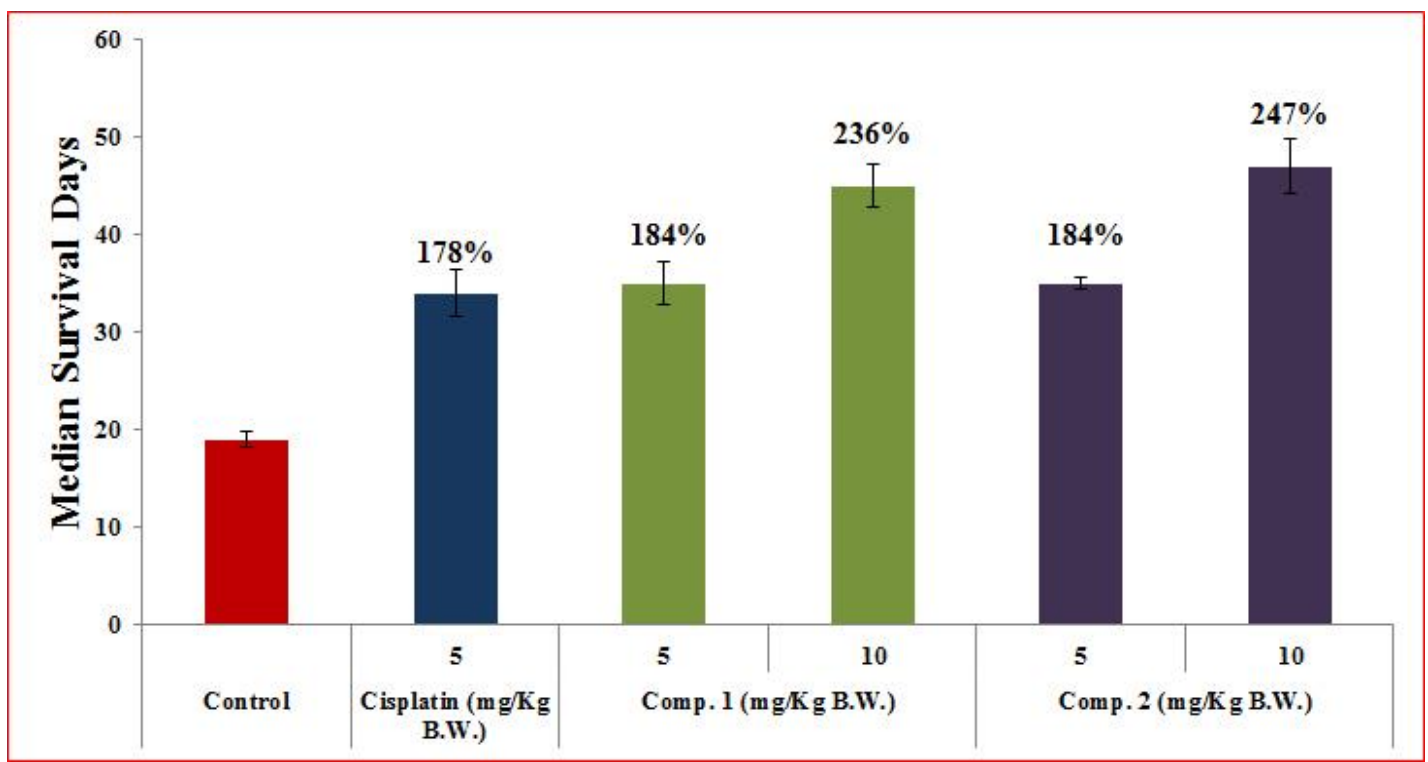

Figure 2: Antitumor activity of Comp. 1 and 2 with control and positive control (Cisplatin $5 \mathrm{mg} / \mathrm{kg} \mathrm{B.W.)} \mathrm{in} \mathrm{DL}$ bearing mice. The treated/control (T/C) values are shown in percentage (\%).

\begin{tabular}{lllllll}
\hline Experimental Condition & $\begin{array}{l}\text { No. of } \\
\text { animals }\end{array}$ & $\begin{array}{l}\text { Treatment } \\
\text { days }\end{array}$ & $\begin{array}{l}\text { Median survival time } \\
\text { (days) }\end{array}$ & $\begin{array}{l}\text { Range } \\
\text { time }\end{array}$ & $\begin{array}{c}\text { survival } \\
\text { T/C } \\
\%\end{array}$ \\
\hline Control & -ve (PBS) & 6 & $6^{\text {th }}, 12^{\text {th }}, 18^{\text {th }}$ & 19 & $18-20$ & \\
& + ve (cisplatin) & 6 & $6^{\text {th }}, 12^{\text {th }}, 18^{\text {th }}$ & 34 & $30-36$ & 179 \\
Comp. & $5 \mathrm{mg} / \mathrm{kg}$ & 6 & $6^{\text {th }}, 12^{\text {th }}, 18^{\text {th }}$ & 35 & $32-37$ & 184 \\
$\mathbf{1}$ & $10 \mathrm{mg} / \mathrm{kg}$ & 6 & $6^{\text {th }}, 12^{\text {th }}, 18^{\text {th }}$ & 45 & $43-49$ & 237 \\
Comp. & $5 \mathrm{mg} / \mathrm{kg}$ & 6 & $6^{\text {th }}, 12^{\text {th }}, 18^{\text {th }}$ & 35 & $32-38$ & 184 \\
$\mathbf{2}$ & $10 \mathrm{mg} / \mathrm{kg}$ & 6 & $6^{\text {th }}, 12^{\text {th }}, 18^{\text {th }}$ & 47 & $44-53$ & 247 \\
\hline
\end{tabular}

Table 1: Median survival days and T/C value of Cisplatin, comp. 1 and 2 towards Dalton's Lymphoma bearing mice.

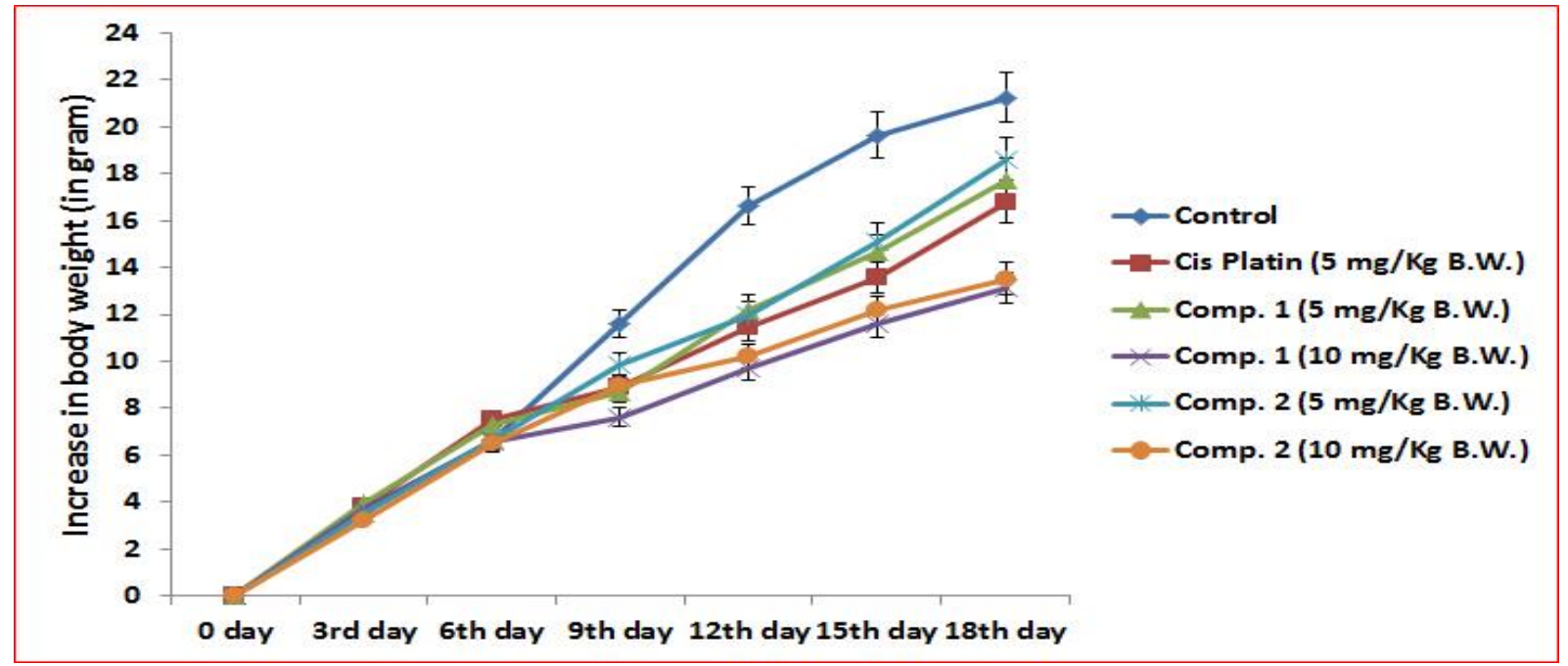

(A) 


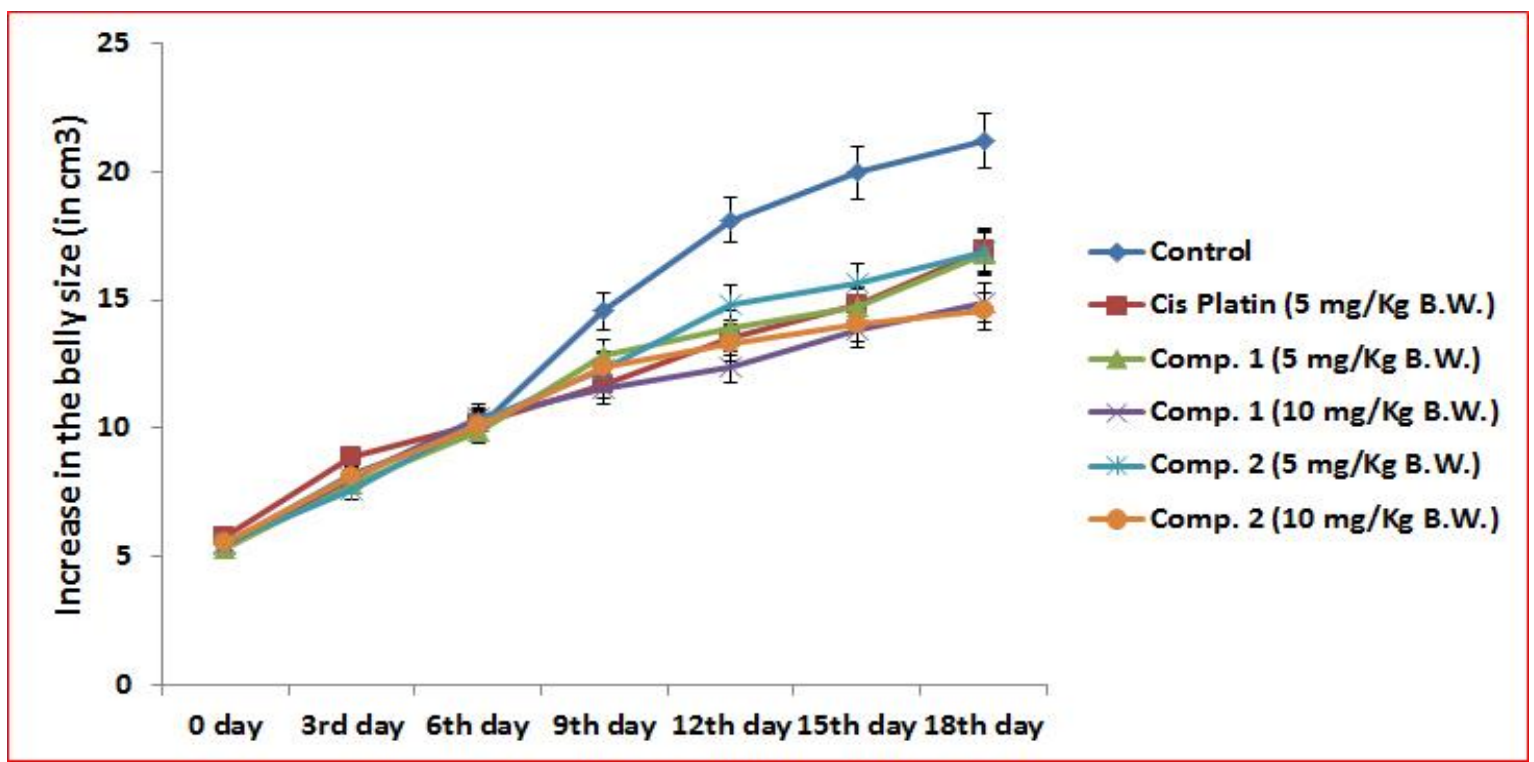

(B)

Figure 3: Effect of complexes on (A) body weight and (B) belly size growth pattern of DL bearing mice. Body weight of Dalton's lymphoma (DL) bearing mice and treated mice from day 0 to 18 after DL transplantation. Values are expressed as mean \pm S.E. obtained from 3 different sets of experiments.

\section{ACKNOWLEDGMENTS:}

The authors highly thankful to Prof. D. S. Pandey, Department of Chemistry, Institute of Science, Banaras Hindu University, for providing the Ruthenium-arene complexes. Gunjan Sharma thanks the "University Grant Commission (UGC), New Delhi" for the award of Senior Research Fellowship [UGCRFSMS, F.5-107/2007 (BSR)]. The authors also acknowledge the Head, Department of Zoology, Institute of Science, Banaras Hindu University, Varanasi (U.P.) India, for extending laboratory facilities.

\section{CONCLUSIONS:}

In the present studies, the effect of both Rutheniumarene complexes in murine lymphoma were found to be dose dependent manner and enhanced more than two fold in the life span of tumor bearing mice and also reduced body weight which represents tumor weight and belly size i.e. equivalent to tumor volume. Lower dose of both Ru-arene complexes demonstrate equivalent efficacy to cisplatin in life span increment and regression in tumor growth. Antitumor efficacy of both complexes was shown by enhancing life span along with suppressing tumor growth of DL bearing mice. Through above results it can be concluded that the both Ru-arene complexes possess anticancer activity in in vivo condition and may be significant implications for the future perspective in cancer management and drug development.

\section{REFERENCES}

[1] Reedijk J., Improved understanding in platinum antitumour chemistry. Chem. Commun, 7: 801-806, (1996)

[2] Wong E. and Giandomenico C. M., Current status of platinum-based antitumor drugs. Chem. Rev, 99: 24512466 (1999)

[3] Chu G., Cellular responses to cisplatin. The roles of DNAbinding proteins and DNA repair. J. Biol. Chem, 269: 787-790, (1994)

[4] Cvitkovic E. and Bekradda, M., Oxaliplatin: A new therapeutic option in colorectal cancer. Semin. Oncol, 26: 647-662, (1999)

[5] O'Dwyer P. J., Stevenson, J. P., and Johnson, S. W., Clinical pharmacokinetics and administration of established platinum drugs. Drugs, 59: 19-27, (2000)

[6)] Reedijk J., Why does cisplatin reach guanine-N7 with competing S-donor ligands available in the cell? Chem. Rev, 99: 2499-2510, (1999)

[7] Clarke M. J., Zhu F., and Frasca D. R., Non-platinum chemotherapeutic metallopharmaceuticals. Chem. Rev, 99: 2511- 2534, (1999)

[8] Guo Z. and Sadler P. J., Metals in medicine. Angew. Chem. Int. Ed. Engl, 38: 1512-1531, (1999) 
[9] Depenbrock H., Schmelcher S., Peter R., Keppler B. K., Weirich G., Block T., Rastetter J. and Hanauske A. R., Preclinical activity of trans-indazolium [tetrachlorobisindazoleruthenate (III)] (NSC 666158; Ind CR.; KP 1019) against tumor colony forming units and hematopoietic progenitor cells. Eur. J. Cancer, 33: 2404-2410, (1997)

[10] Lipponer K.G., Vogel E. and Keppler B.K., Synthesis, characterization and solution chemistry of transIndazolium tetrachlorobis (Indazole) Ruthenate(III), a new anticancer ruthenium complex. IR, UV, NMR, HPLC investigations and antitumor activity. Crystal Structures of trans-1-Methyl-Indazoliumtetrachlorobis-(1Methylindazole) Ruthenate (III) and its Hydrolysis Product Trans-Mono aquatrichlorobis-(1Methylindazole)-Ruthenate(III). Met Based Drugs, 3(5): 243-60, (1996)

[11] Sava G., Alessio E., Bergamo A. and Mestroni G., Sulfoxide ruthenium complexes: non-toxic tools for the selective treatment of solid tumor metastases. Top. Biol. Inorg. Chem, 1: 143-169, (1999)

[12] Srivastava S. C., Richard P., Meinken G. E., Larson S. M. and Grunbaum Z., Tumor uptake of radioruthenium compounds. In Radiopharmaceuticals Structure Activity relationships. Spencer, R. P., Ed. Grune \& Stratton Inc.: New York, pp 207- 223, (1981)

[13] Sava G., Pacor S., Zorzet S., Alessio E. and Mestroni G., Antitumour properties of dimethylsulphoxide ruthenium (II) complexes in the Lewis lung carcinoma system. Pharmacol. Res, 21: 617-628, (1989)

[14] Gupta R. K., Pandey R., Sharma G., Prasad R., Koch B., Srikrishna S., Li PZ, Xu Q. and Pandey D. S., DNA binding and anti-cancer activity of redox-active heteroleptic piano-stool $\mathrm{Ru}(\mathrm{II}), \mathrm{Rh}(\mathrm{III})$, and $\mathrm{Ir}(\mathrm{III})$ complexes containing 4- (2-methoxy pyridyl) phenyl dipyrromethene. Inorg. Chem, 52: 3687-3698, (2013)

[15] Gupta R. K., Sharma G., Pandey R., Kumar A., Koch B, Li $\mathrm{PZ}, \mathrm{Xu} \mathrm{Q}$. and Pandey D.S., DNA/protein binding, molecular docking, and in vitro anticancer activity of some thioether-dipyrrinato complexes. Inorg. Chem, 52: 13984-13996, 2013

[16] Goldie H. and Felix M. D., Growth characteristics of free tumor cells transformed serially in the peritoneal fluid of mouse. Cancer Res, 11: 73-80, (1951)

[17] Kumar A. and Singh S. M., Effect of tumor growth on the blastogenic response of splenocytes: a role of macrophage derived nitric oxide. Immunol. Invest, 25: 413-423, (1996)

[18] Goldie H. and Dingman F. M., Growth characteristics of free tumor cells transferred serially in the peritoneal fluid of the mouse. Cancer Res, 11: 73-80, (1951)
[19] Ahluwalia G. S., Jayaram H. N., Plowhan J. P., Cooney D. A. and Johns D. G., Studies on the mechanism of activity of 2- $\beta$-dribofuranosyl thiazol-4-carboxamide. Biochem. Pharmacol, 33: 1195-1203, (1984)

[20] Anon., "Instruction 14, screening data summary interpretation and outline of current screen," National Cancer Institute, Drug Evaluation Branch, Bethesda, MD, USA, (2014)

[21] Alley M.C., Hollingshead M. G., Dykes D. J. and Waud W. R., Human tumor xenograft models in $\mathrm{NCl}$ drug development. In: Teicher BA, Andrews PA, editors. Cancer Drug Discovery and Development: Anticancer Drug Development Guide: Preclinical Screening, Clinical Trials, and Approval. 2nd ed. Totowa, NJ: Humana Press, Inc, pp. 125-152 (2004)

[22] Yoshikawa T., Kokura S., Tainaka K., Naito Y. and Kondo M., A novel cancer therapy based on oxygen radicals. Cancer Res, 55: 1617-1620, (1995)

[23] Clarke M. J., Galang R. D., Rodriguez V. M., Kumar R., Pell S. and Bryan D. M., In Platinum and Other Metal Coordination Compounds in Cancer Chemotherapy. Martinus Nijhoff: Boston, MA, pp. 582-600, (1988)

[24] Peiper T. and Keppler, B. K., Tumor-inhibiting Ruthenium complexes- formulation and analytical characterization. Analusis Magazine, 26: 84-87, (1998)

[25] Chatterjee S., Subhadip K., Bhattacharyya A., Hartinger G., Christian and Dyson P.J., The Ruthenium (II) arene compound RAPTA-C induced apoptosis in EAC cells through mitochondrial and P-53-JNK pathway. J. Biol. Inorg. Chem, 13: 1149-1155, (2008)

[26] Frasca D., Ciampa J., Emenson J., Umans R.S. and Clarke, M. J., Effects of hypoxia and transferring on toxicity and DNA binding of Ruthenium antitumor agents in HeLa cells. Metal Based Drugs, 3: 197-201, (1996)

[27] Gonzalez-vilchez V., Recent advances on the pharmacological and anticancer applications of Ruthenium complexes. Metal compounds in cancer chemotherapy, ISBN 81-7736-277-1, 321-354, (2005)

[28] Novakova O., Kasparkova O., Vrano O., Vanviet P. M., Reedijk J. and Brabec V., Correlation between cytotoxicity and DNA binding of polypyridyl Ruthenium complexes. Biochemistry, 34: 12369-12378, (1995)

[29] Koiri R. K., Trigun S. K., Mishra L., Pandey K., Dixit D. and Dubey, S. K., Regression of Dalton's lymphoma in vivo via decline in lactate dehydrogenase and induction of apoptosis by a Ruthenium (II)-complex containing 4carboxy N-ethylbenzamide as ligand. Invest. New Drugs, 27: 503-516, (2009).

\section{* Corresponding Author: Biplob Koch*}

Email:kochbiplob@gmail.com 